\title{
A História Filosófica de Voltaire: Sentido e Contexto Intelectual
}

Pedro Henrique Issa

\section{Resumo:}

Os séculosXVIeXVII haviam mergulhado a História em um mar de incertezas, de mitos e fábulas. A História caía em descrédito intelectual generalizado, sendo relegada ao estatuto de "curiosidade", o mais distante possível da produção de conhecimento. Duas grandes correntes foram responsáveis por essa situação: de um lado a crise pyrrhonienne, o ceticismo da era moderna; de outro, as investidas da nova ciência e da filosofia mecânica. Entretanto, no século XVIII, advém a "História Filosófica" proposta por Voltaire em primeira mão, uma tentativa bem-sucedida de resgatar o valor da História no período. Este artigo insere a obra de Voltaire nesse contexto intelectual, não apenas estudando as propostas de sua "História Filosófica", mas também seu significado histórico.

Palavras-chave: História Filosófica - Voltaire - Teoria da História Ceticismo - Revolução Gientífica. 


\section{A Reforma e a Crise Pirrônica}

Vejamos o cenário intelectual da Europa nos idos do século XVI. No despertar da primeira modernidade, as ousadas peripécias de Martinho Lutero já haviam sido consagradas por seus aliados e lamuriosamente reconhecidas por seus inimigos. De I505 a I5I5, a verdadeira preocupação de Lutero, o que lhe atormentava o sono e incomodava seus dias, era a salvação de sua própria alma, sua pauta essencial de levar a si mesmo ao reino dos céus. ${ }^{I}$ Produto desse longo enclaustro em busca de Deus, em busca de uma palavra que o tranquilizasse e lhe assegurasse a dignidade da salvação, Lutero forjou nas brasas do desespero sua doutrina da Sola Fidei, e, suportando-a, a não menos importante Sola Scriptura. Conforme a Igreja de Roma via frustrada sua política de ostracismo e indiferença em relação a Lutero, começou a se preparar para o embate frontal contra o monge que abusava da paciência católica. O palco do confronto seria a Dieta de Worms, em I52I, quando Carlos V determinaria, pelo Édito de Worms, que "nós proibimos qualquer um, deste momento em diante, a desafiar, seja por palavras ou julgamentos, a receber, defender, sustentar ou favorecer o dito Martinho Lutero. Ao contrário, queremos que ele seja apreendido e punido como um herético notório, como ele merece...”.2 A sentença nunca foi compelida com vigor, e logo a batalha seria relegada a uma guerra livresca e panfletária entre Lutero e os fiéis petrinos.

Lutero pretendeu uma razão eficiente nos recursos hermenêuticos bíblicos, uma razão que dispensava a lentidão e a obtusidade dos concílios e dos livros infindáveis de teologia para apreender a Palavra de Deus. Isso não significa que todos os desígnios divinos agora fossem rebaixados ao platô do escrutinável ou inteligível, mas que o cotidiano e as responsabilidades dos cristãos eram passíveis de serem estabelecidas pela leitura privada da Bíblia, que a moralidade e os ditames comportamentais eram tão imediatos quanto o ato de ler o permite ser. O grande problema levantado por Lutero não era puramente seu solifideísmo e seu soliescriturismo, mas era a crítica à instituição da Igreja Católica Apostólica Romana como o único e verdadeiro critério para o estabelecimento das questões de fé. A partir de então, as considerações escolásticas não seriam nada além de "opiniões tomistas", e não mais verdades indeléveis. Lutero transladava o critério de assentamento das verdades de fé para alhures, para a conjunção entre Escritura e consciência, e não mais na infalibilidade do papa e da igreja.

Os católicos não fizeram gosto algum pela coisa. Vendo que a carnificina já

I DELUMEAU, Jean. Nascimento e afirmação da reforma. São Paulo: Pioneira, I989, pp.59-83.

2 SEEBOHM, Frederic. The Era of the Protestant Revolution. Adamant Media Corporation, 2005, pp.125I27. 
não era uma opção saudável, desembainharam armas que haviam adormecido por longo tempo: o Sexto Empírico e as argumentações céticas. Assim, optaram por trazer a disputa ao terreno da razão humana, e, seguindo a prescrição de Sexto Empírico, esbanjaram argumentos contrários à pretensão luterana de uma racionalidade capaz de compreender, nua e crua, a Verdade bíblica.

O primeiro a responder com timbre cético às invectivas de Lutero foi Erasmo de Roterdã. O humanista batavo, em De Libero Arbitrio, apontara que a certeza de Lutero não era nem mais nem menos precisa que a do papa, e, portanto, não havia razão para se abandonar a fé católica. ${ }^{3}$ Em suas palavras, "os assuntos humanos são tão obscuros e diversos que nada se pode saber com clareza". Agora bem, se as certezas tangíveis pelo homem são de natureza tão frágil e tão insólita, como Lutero poderia arrogar-se o direito à Verdade? Como aferir se a razão de Lutero era melhor ou pior que a da Igreja? Por via das dúvidas, nos diz Erasmo, é melhor que nos filiemos incondicionalmente à tradição, e não inconsequentemente à novidade. A crítica aos critérios da verdade que decorria dos escritos de Lutero abria caminho ao pantanoso terreno das anarquias religiosas, e por isso a melhor opção era conservar-se no catolicismo.

Mas Lutero jamais aceitaria que um cristão pudesse ser cético. Ao contrário, o cristianismo é necessariamente dogmático, pois a Palavra de Deus é inapelavelmente verdadeira. Senão, "como ele [cristão] pode acreditar naquilo de que duvida?" Em termos ainda mais lacônicos, Lutero responderia a Erasmo, em seu De Servo Arbitrio, que "o Espírito Santo não é cético”. ${ }^{5}$ Mais tarde, Calvino inseriria ainda um outro critério de garantia da verdade: a "persuasão interior que através do Espírito Santo nos permite este discernimento". ${ }^{6} \mathrm{O}$ percalço deste crivo é bastante trivial: é a subjetividade da "persuasão interior", é legitimar essa experiência enquanto verdade divinamente orientada e não uma loucura prosaica, um achismo banal, uma opinião conveniente ou um falso entusiasmo. ${ }^{7}$ Emblemática é a morte de Servet. Este, em oposição à "persuasão interior" de Calvino, estava - para seu azar - "interiormente persuadido" da falsidade da Santíssima Trindade. ${ }^{8}$

Em suma, nos diz Popkin, "o núcleo intelectual desta batalha da Reforma consistia na busca de uma justificativa para a verdade infalível em questões

3 POPKIN, Richard. História do Ceticismo. Rio de Janeiro: Francisco Alves, 2000, pp.7-9.

4 ROTERDÃ, Erasmo Apud POPKIN, op.cit., p.30.

5 LUTERO, Martinho Apud POPKIN, op.cit., pp.32-33.

6 CALVINO, João Apud POPKIN, op.cit., p.36.

7 POPKIN, op.cit., p.I3O.

8 Idem, p.36. 
religiosas por meio de um critério que fosse autoevidente ou que justificasse a si mesmo". Enquanto isto não adviesse, ambas as posições estariam em apuros. Do ponto de vista protestante, um bom exemplo em uso era a suposta infalibilidade do papa. Se o papa, e apenas o papa, era infalível, quem poderia elegê-lo infalivelmente? Se o Concílio que o consagra é falível, como garantir que o papa é realmente infalível? Já do ponto de vista católico, o máximo que os reformadores conseguiriam era substituir a pretensa falibilidade do papa, como acreditavam, pela falibilidade individual e pessoal dos homens. Afinal, se o papa era falível, por que outro homem também não o seria? - lançando assim a religiosidade em um domínio incerto e inóspito.

Um homem em especial que havia colhido os frutos dessa restauração pirrônica foi Michel de Montaigne. Mas o ceticismo de Montaigne ainda era recheado de fideísmo, na crença de que, diante da precariedade da razão, devemos nos subordinar à fé pura e simples. Tal premissa seria o elemento basilar da Contra-Reforma francesa. As ideias de Montaigne, de Charron e de Camus seriam acolhidas calorosamente por homens como Hervet, Gontery e Veron. Os líderes católicos franceses e os controversistas jesuítas empregariam com gosto os argumentos pirrônicos na demolição do calvinismo, e as filiações entre eles eram muitas vezes afetivas e pessoais, extrapolando a mera cumplicidade intelectual. ${ }^{10}$

\section{Revolução Científica e Pirronismo Histórico}

É só um pouco mais tarde que a crise pyrrhonienne, a crise pirrônica, dissociase das querelas religiosas. Isso é obra dos libertins érudits, do círculo dos libertinos eruditos franceses, cujos nomes mais conspícuos foram Gabriel Gudé, Guy Patin, François de La Mothe Le Vayer, Samuel Sorbière e Isaac La Peyrère. ${ }^{\text {II }}$ Nas palavras de Popkin, "com o começo da reforma científica e a crítica ao sistema de Aristóteles, o ataque cético rapidamente ampliou o problema tornando-o um ataque às bases de todo o conhecimento. Nas duas ordens do conhecimento humano, revelado e natural, os fundamentos desapareceram". ${ }^{12} \mathrm{O}$ pirronismo agora investia contra a astrologia e contra a alquimia. Mersenne considera o ataque de Francis Bacon à ciência escolástica uma produção essencialmente pirrônica, e Gassendi fora um pirrônico declarado que mobilizou uma vasta gama de argumentos céticos contra a ciência tradicional.

\footnotetext{
9 Idem, p.42.

IO Idem, pp.I44-I45.

II Idem, p.I53.

I2 Idem, p.I84.
} 
Assim, o ceticismo se propala pelas diversas esferas do conhecimento. Um desses domínios a ser castigado pelo terremoto pirrônico foi a História. A História até então praticada, fundamentava suas certezas na tradição oral e na documentação escrita. A filologia humanista, coroada com Lorenzo Valla, já se encarregara de domar os textos e escancarar algumas falácias históricas, restava agora ao ceticismo e à ciência moderna dar sua lição aos fenômenos naturalmente incabíveis e historicamente espúrios.

No século XVII, o homem passou a se importar mais com sua realidade imediata e menos com as supostas verdades impressas. Um dos primeiros a professá-lo e desfazer-se desse saber catalogado foi Francis Bacon. ${ }^{13}$ Sua tradição empirista, somada à pretensão matemática platônico-pitagórica (ou arquimediana), com a recente "filosofia mecânica" corpuscular, ancorada no atomismo, purgava todo e qualquer vestígio de surrealidade do mundo. A matemática e a experimentação aniquilaram a possibilidade da magia e do milagre, debochando e confutando tudo que fosse místico e oculto em vez de claro, transparente e distinto. ${ }^{14}$ É o período nuclear da chamada Revolução Gientífica. O século XVII assiste ao surgimento de uma nova epistemologia, de uma nova concepção de Natureza. Bacon defendia um método empírico para acessá-la e Galileu procedia com a matematização dessa natureza. Essas duas grandes linhas iriam desembocar na consagrada síntese newtoniana, a nova concepção científica que seria responsável por desvendar as Leis da Natureza e romper a barreira dos milagres e prodígios. São essas novidades epistemológicas, somadas à crítica pirrônica que entrou pela porta do mosteiro, que deglutiram os livros de história entre os séculos XVI e XVII.

O papel do ceticismo foi descreditar os fenômenos sobrenaturais, arrolandoos como suspeitos, e à ciência coube estipular tudo que era plausível de acordo com as leis da física, ou, ainda melhor, com as leis da natureza, traçando assim a linha limítrofe entre mito e verdade dos relatos históricos. Também à ciência coube aplicar, pela primeira vez com sucesso, a matemática no entendimento da natureza, instaurando o que já foi chamado de "universo da precisão". ${ }^{15}$

Tudo isso representou um funesto golpe na História. Em sua "árvore do conhecimento", Descartes não reservou sequer um modesto graveto para a História. A História não produz nem faz parte do conhecimento, ${ }^{16}$ ela é, no

I3 ROSSI, Paolo. Francis Bacon: da magia à ciência. Londrina: Eduel, 2006, pp.I45-I97.

I4 A leitura clássica da Revolução Científica como triunfo da racionalidade humana é apresentada em HALL, A.R. The Scientific Revolution, 1500-1800. Londres: Longmans, I954.

I5 KOYRÉ, Alexandre. "Do 'mundo do mais ou menos' ao universo da precisão", in: Estudos de história do pensamento filosófico. Rio de Janeiro: Forense Universitária, I99I.

I6 GOHEN, I.B. Revolution in Science. Massachusetts: Harvard University Press, 200I, p. I53. 
máximo, um passatempo. Leibniz, por exemplo, defenderia o valor da História enquanto provedora de curiosidades, e Malebranche iria mais longe, dizendo que não passa de compilação de fofocas. ${ }^{17} \mathrm{E}$ que "o novo método [cartesiano] procurava eliminar tudo o que não pudesse ser justificado pelo uso sistemático de métodos racionais", nos diz Berlin. Ou seja, a História era inapreensível e inexprimível por meio da matemática, e a matematização da natureza estava na ordem do dia no século XVII. ${ }^{18}$ Assim, pela pena de Descartes, é dada entrada judicial no divórcio entre as ciências e as humanidades. Descartes confisca da História o distintivo de ciência, deixando-a abandonada e sem abrigo científico até o século XVIII. (Giambattista Vico, por sua vez, assinaria a papelada com separação de bens, criando finalmente um novo teto científico para a História, um método próprio que nada deixava a dever ao do francês. ${ }^{19}$ Mas Vico não viu tão cedo a luz do sol, e os homens o presentearam com o esquecimento por um bom tempo, tratando-o exatamente pelo que ele era: um napolitano obscuro, místico e provinciano).

Essa era, portanto, a situação da História nos finais do século XVII: desprezada e moribunda, flagelada pela ciência, colhendo os vitupérios do ceticismo e sangrando as investidas da descrença. Naquele momento, um homem pensou que apenas uma coisa era capaz de salvá-la e garantir-lhe uma sobrevida: a razão. E esse homem, o primeiro que se propôs a fazê-lo, fora Voltaire.

\section{A História Filosófica: Soteriologia, Pedagogia e Racionalidade}

Costuma passar despercebido que esse teor soteriológico era a verdadeira razão de ser da História Filosófica atinada por Voltaire. A História, ficando entregue aos historiadores, tinha como destino inevitável definhar no leito da mentira. O conjunto das obras históricas até ali produzidas era um espetáculo elegíaco de mitos, fábulas, mentiras e adulações, uma ode triunfal à ignorância e uma ofensa descabida ao espírito livre. Uma história filosófica seria o fim dessas trevas e a aurora da História enquanto ciência. Vejamos, então, como ela se comporta.

I7 BERLIN, Isaiah. "O divórcio entre as ciências e as humanidades", in: Estudos sobre a Humanidade. São Paulo: Companhia das Letras, 2002, pp.353-355.

I8 Para uma visão da "matematização da natureza" como chave de leitura da Revolução Científica, ver KOYRÉ, Alexandre. Estudos Galilaicos. Lisboa: Publicações Dom Quixote, I986, e DIJKSTERHUIS, E.J. The mechanization of the world picture. New York: Oxford University Press, I969.

I9 BERLIN, op.cit., pp.349-378. 


\section{O papel da filosofia}

A filosofia vem abocanhar a tarefa do historiador, em primeiro lugar, porque só a razão é capaz de iluminar esse limo no qual chafurdava a História. ${ }^{20}$ O historiador, enquanto tal, poderia no máximo averiguar as credenciais de uma fonte. Porém, crédito conferido, a ele só caberia acreditar nos milagres e outras presepadas ali relatados. O filósofo, ao contrário, portando o cetro do bom senso e desnudando as leis da natureza, seria o homem mais talhado para dizer o que de fato se passou. Porque, afinal de contas, tudo aquilo que se passou só pode ser aquilo possível de ocorrer, de acordo com os ditames da natureza. Ditames estes que, sem grandes surpresas, eram ajuizados por ninguém menos que o filósofo, o filósofo natural. Portanto, a História Filosófica vem despir as mentiras e embustes das narrativas de até então.

Assim é que Voltaire opõe categoricamente a História à Fábula, ${ }^{21}$ e, por tabela, a história fabulosa à história filosófica, ${ }^{22}$ dicotomia que se funda na tensão epistemológica entre conhecimento e opinião, que se arrasta, pelo menos, desde Sócrates. Ou seja, a "nova história”, a história por ele proposta, difere profundamente da fábula, ao passo que as histórias que chegaram até ele dificilmente poderiam arrogar para si essa façanha. Depreciar a história recheada de fantasia lhe consome boa parte do fôlego: Voltaire lança um anátema voraz sobre a tradição oral, fustigando-lhe a culpa das deturpações e diatribes que imperam nos supostos acontecimentos históricos, donde segue que a verdadeira história deve ser impreterivelmente escrita. ${ }^{23}$

Mas isso, por si só, não basta. Sendo a escrita apanágio de clérigos e pensionistas da corte, as falácias que um deixar de escrever em nome dos santos, o outro certamente escreverá em nome dos reis. Aqui, portanto, a segunda missão do filósofo enquanto sacerdote da razão: a imparcialidade. A ideia da imparcialidade é formulada no seio de uma tradição crítica pretensamente apolítica. É o teatro de Lessing, os contos filosóficos, a pintura engajada, é tudo que corre à margem dos discursos políticos, mas critica a imoralidade deliberada do Estado absolutista. São vozes que se colocam acima da discussão política e que, por isso mesmo, seriam "apartidárias". ${ }^{24}$ Voltaire é, ao mesmo tempo, herdeiro e arauto dessa crítica dissimulada, e é assim que consegue, na

20 SOUZA, Maria das Graças de. Ilustração e História. São Paulo: Discurso Editorial, 200I, p.I4I.

2I Verbete "História" da Enciclopédia, in: VOLTAIRE. A filosofia da história. São Paulo: Martins Fontes, $2007, \mathrm{p} \cdot 3$.

22 Idem, p.4.

23 VOLTAIRE, op.cit., p.7.

24 KOSELLECK, Reinhart. Crítica e crise. Rio de Janeiro: Contraponto, I999, pp. 88-IO2. 
maior parte do tempo, provocar seus próprios interlocutores nas conversas de salão e sair, quase sempre, ileso. O filósofo do século XVIII é, por excelência, aquele que se encontra acima das miudezas políticas e dos conflitos terrenos, é um intocável que existe para julgar sem nunca ser laçado pelo juízo dos homens, ele é, desde já, um Zaratustra. Voltaire condena o fato de que as páginas das histórias estejam "sujas de imposturas e termos ofensivos", e diz que isso "não é escrever história, é escrever ao sabor das calúnias dignas do pelourinho". ${ }^{25}$ Dessa preocupação é que surge a diferenciação entre "la critique, la satire et la libelle", ${ }^{26}$ sendo as últimas registros despropositados de difamação gratuita. Ao contrário, elogia a "imparcialidade, gravidade e sabedoria", e não deixa de refletir "como é de se temer que o pincel seja guiado pela paixão!" ${ }^{77}$ Pincel temido que, por sinal, tem endereço certo nas mãos do "historiógrafo", aquele que é o historiador oficial do rei - razão pela qual "é bem difícil não ser um mentiroso". ${ }^{28}$

O terceiro e último propósito da invasão filosófico-racionalista no terreno histórico diz respeito exatamente ao objetivo da disciplina. Não incomoda Voltaire que o pirronismo tenha lançado os documentos à areia movediça, porque a História Filosófica não se preocupa com as minúcias dos pequenos fatos, com as ninharias dos mínimos eventos. Não, a história feita pelos homens de luzes é outra, a história dos homens de razão e inteligência é muito maior que isso: propõe-se a investigar qual é o "espírito de um povo". ${ }^{29}$ Detenhamo-nos um pouco neste ponto.

Olhando por cima dos ombros, Voltaire enxerga quatro "grandes eras" em toda a história da humanidade. A primeira é devida à síntese helenística de Alexandre, a segunda fala da grandeza de Augusto, a terceira é o saudosismo do Renascimento, e a quarta e última é a obra triunfal de Luís XIV. ${ }^{30}$ (É também edificante constatar que, ao contrário dos renascentistas que sempre veem o início do Império como o marco fúnebre da civilização romana, Voltaire, pela primeira vez, vê em Augusto justamente o paroxismo do desenvolvimento das faculdades do espírito humano). Agora bem, fato importante, a magnificência dessas eras não é devida à perícia política ou militar desses homens. Voltaire passa na história uma régua de medida cultural no sentido moderno, ou civilizacional e costumeiro nos termos da época. As variáveis que calibram a potência de uma era são fundamentalmente culturais: são os costumes, a religião, as ciências,

25 VOLTAIRE, op.cit., p.23.

26 KOSELLECK, op.cit., p.IOI.

27 VOLTAIRE, op.cit., p.21.

28 Verbete "Historiógrafo" da Enciclopédia, in: VOLTAIRE, op.cit., p.34.

29 SOUZA, op.cit., p.II5.

30 SOUZA, op.cit., p.III. 
artes e filosofia, são as instituições e a economia. ${ }^{3}$ Voltaire reprocha que a notoriedade de um povo se contabilize em hectares de terra ou legiões de soldados, e chega ao limiar de esboçar um culturalismo estruturante a partir do qual mesmo a economia e a política seriam moldadas. ${ }^{32}$ Finalmente, se essas são as categorias a serem avaliadas é porque o produto final de sua combustão é precisamente o "espírito" da civilização em questão, sendo, portanto, esse aspecto geral de um povo o que define seu grau de esplendor ou de horror.

Significa que a função da História, e isso merece destaque, a função e o objetivo último da História, para Voltaire, é desvelar a grandeza dos espíritos dos povos de outrora para ensinar aos homens de hoje e de amanhã os caminhos da glória e da civilização. Ora, se as variáveis culturais são aquelas que definem o espírito de um povo e se o objetivo da História é restaurar o paroxismo desses espíritos, naturalmente a História deve se propor a investigar precisamente esses caracteres culturais de um povo ou de uma nação.

\section{A Função Pedagógica da História}

Elucidemos esse caráter tutorial da História. Voltaire ainda bebe das fontes da História Magistra Vitae. A História tem uma grande função pedagógica para a humanidade, e ele nos diz isso de forma transparente: "Aniquilem o estudo da história, e verão talvez dias de São Bartolomeu na França e Cromwells na Inglaterra". ${ }^{33}$ Lembra-nos também que "uma vantagem que a história moderna tem sobre a história antiga é a de ensinar", e nos assegura que "os exemplos produzem grande efeito no espírito". ${ }^{34}$ Agora, o que deve ser ensinado são, repitamos, os predicados capazes de levar uma civilização a outra "grande era". É só nesse sentido que se compreende a célebre afirmação de que aquele que "não tem mais nada a nos dizer além de que um bárbaro sucedeu a outro" é um homem de nenhuma "serventia ao público". Se não a considerarmos como uma evidente preocupação em estabelecer o espírito de um povo em vez de investigar eventos isolados, automaticamente a tomamos por uma simples crítica à "História Política". Na verdade, ela significa que a História Política é um peso morto para o nobre objetivo da História, e que o pretenso historiador, ao contrário, "devia me informar sobre os direitos da nação, suas leis, seus

3I Idem, ibid.

32 Idem, p.IO3.

33 VOLTAIRE, op.cit., p.I6.

34 Idem, p.I5. 
usos, seus costumes e como eles mudaram". ${ }^{35}$ Com frequência, se comenta as conquistas de Vico para a História, mas convém lembrar que daqui é que sai o prestígio do que viria a ser a História Social em detrimento da História Política.

A História, portanto, ensina. Para tanto, é curioso notar que apesar de um ideal de imparcialidade que reina em seu pensamento, Voltaire não deixa de conferir à História uma responsabilidade jornalística, denunciante e, principalmente, judiciária. Relembrando a condenação de Calas, ${ }^{36}$ nos diz que "é o dever de um historiador inspirar horror a todos os séculos por esses assassinatos", bem como "sempre se deveu fazer os atenienses enrubescerem por causa da morte de Sócrates". O historiador, "recordando as guerras da Fronda e as guerras religiosas, impedem que haja outras como elas". ${ }^{37}$ Tudo muito generoso da parte de Voltaire, especialmente agora que a tarefa de juiz incumbida ao historiador foi transferida à alçada do filósofo.

Ainda nesse terreno instrutivo da História, Voltaire insiste muito no estudo das leis de um povo. Inicia a sessão "Da utilidade da história" sublinhando que esta "consiste, sobretudo, na comparação que um estadista, um cidadão podem [sic] fazer das leis e costumes".$^{38}$ A reincidência no tema pode levar ao equívoco de se aventar uma suposta preocupação com a História Política. Mas não, Voltaire aponta que esses estudos são "o que estimula a emulação das nações modernas nas artes, na agricultura, no comércio". ${ }^{39}$ Mas de que forma? Fica a hipótese: as leis são capazes de refletir o universo (real ou ideal) de um povo, é ali onde melhor se pode captar, pensaria Voltaire, as características fundamentais do funcionamento da sociedade, matéria-prima imprescindível para se instaurar uma nova era de grandezas.

Mas nem só o que há de melhor deve ser registrado. Os maus exemplos são de importância capital para que se possa evitá-los. Assim é que Carlos XII acaba sendo um exemplo a ser abominado, bem como é condenável a imbecilidade de Gregório VII e os episódios tétricos das Guerras de Religião. Nada a ser esquecido, nem mesmo as tolas crendices dos homens, mas tudo a ser prevenido. No limite, o que nos revela esse caráter tutelar da História é justamente a fragilidade da razão humana, que, se viu alguns séculos de luz, sempre teve,

35 Idem, pp. 25-26.

36 Jean Calas(I698-I762) foi um mercador francês que teve sua sentença altamente influenciada pela perseguição à sua fé protestante. Baseado nesse evento, Voltaire propõe-se a escrever seu Tratado sobre a tolerância (I763).

37 VOLTAIRE, op.cit., p.36.

38 VOLTAIRE, op.cit., p.I4.

39 Idem, p.I5. Grifo do autor. 
fatalmente, seus esforços "mergulhados numa escuridão profunda". $4^{\circ}$ É que em Voltaire, enquanto Voltaire, não poderia haver o imperativo categórico de Kant, não poderia haver a inevitabilidade do triunfo racional. A razão humana estava ali, é verdade, mas era preciso travar uma luta sangrenta contra as trevas para emulsionar os lipídios da barbárie que a aprisionavam, sempre cuidando do risco, pelos exemplos a se esquivar, de não se incorrer em outro milênio de obscuridade. A História, em suma, deve auxiliar o homem a instaurar o Império da Razão.

\section{O Combate aos Mitos, a Busca da Verdade}

O que muda derradeiramente é que agora em nada são úteis as histórias recheadas de mitos, temperadas de fábulas e diluídas em milagres. Estes não são mais exemplos fidedignos, e não se pode alcançar uma Grande Era trilhando seus ensinamentos. Agora, é preciso uma história verossímil, por isso "tanto é fácil fazer uma coletânea de mexericos como é hoje difícil escrever a história". "Exige-se dos historiadores modernos mais detalhes, fatos mais constatados, datas precisas, autoridades, mais atenção". "4 A História é mais rigorosa, mais científica. E não se deve temer o uso do termo. As considerações de Voltaire sobre os Elementos da filosofia de Newton deixam claro que seu propósito era fazer uso do edifício metodológico newtoniano nas ciências humanas, ainda que não ipsis literi. Uma breve incursão na epistemologia de Voltaire elucida: "toda certeza que não é demonstração matemática não passa de uma extrema probabilidade", e, mais importante, "não há outra certeza histórica" senão a probabilística. ${ }^{42}$ Ao contrário de Descartes, Voltaire nos diria que há conhecimento certo na História, que existem ainda certezas neste domínio, ainda que certezas probabilísticas. Este é Voltaire empregando, talvez, o método de "graus de aceitação" desenvolvido por seu mestre John Locke, ${ }^{43}$ este também fornecendo uma das matrizes de esquiva ao beco escuro do ceticismo.

Dois são os critérios que definem o grau de probabilidade de um fato histórico. Em primeiro lugar, e eliminatório, vem a factibilidade do fenômeno. Ou seja, "o que contraria o curso ordinário da natureza não deve ser digno de crédito". Em seguida, há a quantificação dos testemunhos: "dois ou três historiadores" não podem valer mais que "várias testemunhas oculares".

40 Idem, p.II.

4 I Idem, p. 25 .

42 Idem, p.I6.

43 BURKE, Peter. Uma história social do conhecimento. Rio de Janeiro: Jorge Zahar, 2003, p.I85. 
Portanto, o primeiro crivo é de caráter científico e pressupõe uma natureza e uma realidade eterna, donde aquilo que hoje nos parece absurdo e impossível ontem certamente também o foi. O segundo é de natureza aritmética, uma simples operação de medição. Esse, portanto, o método de verificação histórica de Voltaire: atestada a plausibilidade do fato, passa-se a computar as evidências. Mas cabe apontar que, paradoxalmente, ele arremessa aos ares essa ferramenta de certeza quando cogita a existência de fatos absurdos, contanto que seja tudo "atestado por homens visivelmente animados pelo espírito divino", ${ }^{44}$ terreno no qual a certeza é já absolutamente escorregadia.

\section{O tempo dos homens e a queda possível}

A última e breve questão que se coloca: qual seria a noção de tempo histórico de Voltaire? Gertamente, ele rejeita a circularidade plena: ironizando o restauracionismo dos renascentistas, Voltaire os instrui a "dizer ao mar: estiveste outrora em Aigues-Mortes, Fréjus, Ravena, Ferrara; volta lá daqui a pouco". ${ }^{45}$ Mas é possível questionar: se a História não é circular e não se repete, como qualquer exemplo pode ser útil? Na verdade, a História possui uma potencialidade para se repetir, mas não o faz precisamente por conta de seus ensinamentos. É porque temos exemplos que não incorremos nos mesmos erros e conseguimos com isso progredir, é porque temos o tribunal da História que o homem pode avançar em sua marcha. Acerca dos crimes e desgraças da humanidade, Voltaire afirma que "digam o que quiserem, mas pode-se prevenir aqueles e estas", e, como carga de prova, "a história do tirano Cristiano pode impedir que uma nação confie o poder absoluto a um tirano". ${ }^{46}$ Portanto, progresso: "os homens se esclarecem pouco a pouco vendo este quadro de suas infelicidades e tolices. As sociedades, com o tempo, retificam suas ideias; os homens aprendem a pensar". ${ }^{47}$

Porém, como vimos, nada impede que o homem recaia no abismo da barbárie. Portanto, há uma linearidade, mas não uma mera laicização da matriz agostiniana do tempo. A linearidade voltairiana não é teleológica, não possui um fim inevitável e laico. Jean Dagen é ainda mais acurado, e traça um novo paradigma de compreensão histórico-temporal desde Fontenelle e sua Histoire des Oracles, publicada dez anos antes do dicionário de Bayle. Nela, a crítica da

44 VOLTAIRE, op.cit., p.I7.

45 Idem, p.I4.

46 Idem, p.I5.

47 SOUZA, op.cit., p.I47. Grifo do autor. 
imaginação mitológica garante uma alternativa à temporalidade cristã, ou seja, a crítica aos mitos e fábulas dá ocasião a um estudo cronológico e temporal diverso do modelo cristão de tempo..$^{48}$ Assim, é a potencialidade à queda e às recaídas, é a não garantia do progresso contínuo aquilo que garante o sentido da História Filosófica: apontar a direção correta da marcha humana rumo às "grandes eras" por meio dos exemplos e das denúncias históricas.

\section{Conclusão}

A Reforma religiosa do século XVI abriu a Caixa de Pandora que trazia, hermeticamente, o problema dos critérios da verdade. Gian Francesco Pico della Mirandola, católico, foi o primeiro a fazer uso das obras de Sexto Empírico, empregando-as contra o sistema aristotélico vigente. Erasmo, por sua vez, foi o primeiro a empregar argumentos céticos em defesa da ortodoxia, contra o protestantismo. A Contra-Reforma Católica esbaldou-se no pirronismo francês para minar as pretensões calvinistas, fazendo farto uso das ideias de Montaigne e Gharron. O século XVII, finalmente, traria a chamada Revolução Gientífica, impondo um novo conceito de Natureza e de Verdade, combatendo os prodígios e oráculos porque em desacordo com as leis naturais.

A História passa a sofrer com o novo cenário intelectual. De um lado, o ceticismo descreditava a veracidade dos relatos históricos, de outro, a "nova ciência", essencialmente matemática, escanteava a história dos domínios científicos. Assim, assediada, deixa suas chagas expostas na espera de alguém que as pudesse curar.

Voltaire encara essa tarefa e vem a socorro da História, propondo a chamada História Filosófica. Seu elemento fundamental seria a razão, e essa razão, aplicada à História, varreria os dejetos míticos dos relatos e ilustraria os picos históricos da civilização humana, ensinando aos homens como fundar e manter uma nova "Grande Era". A ênfase colocada sobre a função pedagógica da História é o núcleo dessa nova proposta, porque nada impede que o homem tropece em seus caminhos e recaia novamente em um período de trevas, já que, ainda "hoje, neste século que é a aurora da razão, algumas cabeças da hidra do fanatismo ainda renascem".

É difícil ir além disso. Em curto prazo, Voltaire vê em Frederico da Prússia a possibilidade de um novo triunfo da razão, mas logo vê frustrada sua aposta. Em longo prazo, não se sabe, Voltaire ainda não teria decifrado as Leis da História e do espírito humano para dizê-lo, uma tarefa colossal que a providência,

48 SOUZA, op.cit., p.I29. 
aparentemente, encarregaria apenas a Hegel, não impondo a Voltaire um fardo maior do que ele poderia carregar.

\section{Referências Bibliográficas}

BERLIN, Isaiah. Estudos sobre a Humanidade. São Paulo: Companhia das Letras, 2002.

BURKE, Peter. Uma história social do conhecimento. Rio de Janeiro: Jorge Zahar, 2003.

CASSIRER, Ernst. A filosofia do iluminismo. Campinas: Editora da UNICAMP, I997.

GOHEN, Bernard. Revolution in Science. Harvard University Press, I987.

COHEN, H.F. The Scientific Revolution: a historiographical inquiry. Chicago: The University of Chicago Press, I994.

DELUMEAU, Jean. Nascimento e afirmação da Reforma. São Paulo: Pioneira, I989.

HALL, A.R. Revolução na Ciência, 1500-1750. Lisboa: Edições 70, I983.

KOSELLEGK, Reinhart. Crítica e crise. Rio de Janeiro: Contraponto, I999.

KOYRÉ, Alexandre. Estudos Galilaicos. Lisboa: Publicações Dom Quixote, I986.

Universitária, I99I.

POPKIN, Richard. História do Ceticismo. Rio de Janeiro: Francisco Alves, 2000 .

ROSSI, Paolo. Francis Bacon: da magia à ciência. Londrina: Eduel, 2006.

SOUZA, Maria das Graças de. Ilustração e História. São Paulo: Discurso Editorial, 200I. 
SEEBOHM, Frederic. The Era of the Protestant Revolution. Adamant Media Corporation, 2005 .

VOLTAIRE. A filosofia da história. São Paulo: Martins Fontes, 2007.

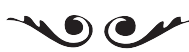

Pedro Henrique R. de O. Issa é graduando em História pela USP.

E-mail: pedro.issa@usp.br 